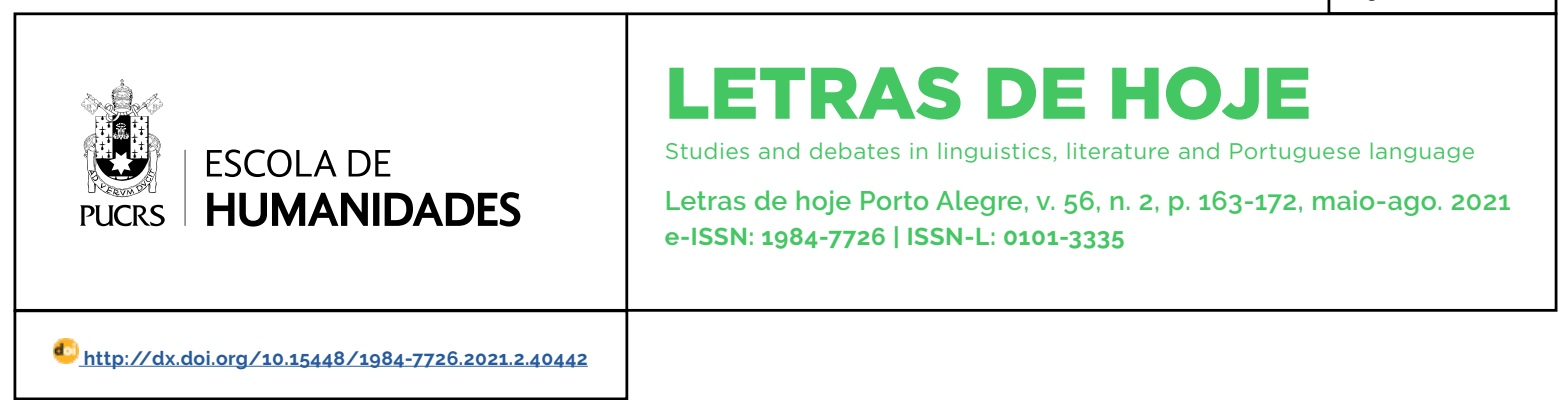

SEÇÃO: O CONTO BRASILEIRO CONTEMPORÂNEO DE AUTORIA FEMININA

\title{
A infância na obra de Monique Revillion
}

\author{
Childhood in the work of Monique Revillion \\ La infancia en la obra de Monique Revillion
}

\section{Kelin Camila Beilke ${ }^{1}$}

orcid.org/0000-0002-4373-5619 kelinbeilke@mx2.unisc.br

\section{Ana Cláudia Munari Domingos $^{1}$}

orcid.org/0000-0002-6629-588X anamunari@terra.com.br

Recebido em: 22 mar. 2021. Aprovado em: 15 ago. 2021. Publicado em: 9 nov. 2021.

\section{(c) (1)}

Artigo está licenciado sob forma de uma licença Creative Commons Atribuição 4.0 Internacional.
Resumo: Neste trabalho trazemos alguns elementos que exemplificam os modos como a infância é representada nos livros Teresa, que esperava as uvas e $O$ Deus dos insetos, que compõem a obra de Monique Revillion. Para tal, fazemos alguns apontamentos acerca dos conceitos de infância e memória, nos contextos social e literário. A memória, aqui, nos interessa a partir da ideia de um narrador adulto que relata um acontecimento da infância. A partir dessa perspectiva, selecionamos os contos que tratam desse tema e analisamos aqueles que trazem personagens crianças e suas ações. O viés de análise parte de um conhecimento sobre o corpus, que mostrou a relação intima entre a infância e a violência como o subtema mais recorrente nas narrativas. A partir dessa leitura e desses exemplos, o trabalho deixa ver a diversidade de vivências apresentadas pelas infâncias na obra de Monique Revillion, bem como algumas implicações dessa relação entre infância e violência, caracterizando o que entendemos como uma "não infância". Palavras-chave: Monique Revillion. Representação da infância. Violência.

Abstract: In this paper we bring some elements that exemplify the ways in which childhood is represented in the books Teresa que esperava as uvas and $O$ deus dos insetos, which make up the work of Monique Revillion. To this end, we begin our analysis with some notes about the concepts of childhood and memory, in the social and literary contexts. Memory, here, interests us from the idea of an adult narrator who recounts a childhood event. In the following, we select the short stories that deal with this theme and analyze those that feature children characters and their actions. The analysis perspective starts from an understanding of the corpus, which showed the intimate relationship between childhood and violence as the most recurrent sub-theme in the narratives. From this reading and these examples, the work lets us see the diversity of experiences presented by childhoods in the work of Monique Revillion, as well as some implications of this relationship between childhood and violence, characterizing what we understand as a "non childhood".

Keywords: Monique Revillion. Representation of childhood. Violence.

Resumen: En este trabajo traemos algunos elementos que ejemplifican las formas en que la infancia es representada en los libros Teresa, que esperava as uvas e $O$ deus dos insetos, que componen la obra de Monique Revillion. Para ello, comenzamos nuestro análisis con algunas notas sobre los conceptos de infancia y memoria, en los contextos social y literario. El recuerdo, aquí, nos interesa desde la idea de un narrador adulto que relata un suceso de la infancia. A continuación, seleccionamos los cuentos que tratan este tema y analizamos los que traen personajes infantiles y sus acciones. La perspectiva de análisis parte del conocimiento del corpus, que mostró la intima relación entre infancia y violencia como el subtema más recurrente en las narraciones. A partir de esta lectura y de estos ejemplos, el trabajo deja ver la diversidad de experiencias que presentan las infancias en la obra de Monique Revillion, asi como algunas implicaciones de esta relación entre infancia y violencia, caracterizando lo que entendemos como una "no infancia".

Palabras clave: Monique Revillion. Representación de la infancia. Violencia.

1 Universidade de Santa Cruz do Sul (Unisc), Santa Cruz do Sul, RS, Brasil. 


\section{A violência como subtema da infância na obra de Monique Revillion}

Neste trabalho nos debruçamos sobre a obra de Monique Revillion, composta de duas coletâneas de contos. Natural de São Leopoldo, cidade gaúcha, Monique iniciou sua carreira no mundo literário em 1997, com a publicação de antologias. Em 2006, publicou seu primeiro livro, Teresa, que esperava as uvas. No ano de 2013, a autora publicou seu segundo livro, O Deus dos insetos. A narrativa de Monique Revillion nos apresenta personagens diversos, que vivem suas vidas em um turbilhão de sentimentos, recorrentemente o medo, a impotência, a dúvida. Dentre esses personagens, percebemos a recorrência de crianças como protagonistas de vivências diversas, tanto o amor e as pequenas conquistas, quanto a violência e a decepção. É nessa representação da infância, a partir de um narrador adulto, que focalizamos nossa atenção.

Em um primeiro momento, buscaremos apresentar algumas ideias mais gerais acerca do que seja a infância, que serão abordadas tanto a partir de seu significado no contexto social quanto no literário, mas de modo algum esgotam suas tantas possibilidades. No contexto social, buscaremos entender como o conceito de infância foi modificado ao longo do tempo e suas principais modificações. No contexto literário, pretendemos analisar brevemente a relevância de personagens infantis ao longo da história literária, além de compreender como a literatura destinada ao público infantil era constituida e sua história até os dias atuais. Relacionaremos, também, os conceitos de infância e memória, buscando compreender a articulação das narrativas que apresentam as duas temáticas.

$\mathrm{Na}$ análise do objeto desse trabalho pretendemos identificar e apontar os principais subtemas que aparecem em concomitância com o tema da infância. Um dos subtemas mais recorrentes que podemos apontar, por exemplo, é o da violência associada à infância. De diversas formas, os contos nos apresentam situações nas quais as crianças sofrem ou praticam violência. Analisaremos, portanto, a temática infantil na obra de Monique Revillion, cotejando enredos e levando em conta esses subtemas.

\section{A representação da infância pela memória}

O conceito de infância pode ser definido através de diferentes ideias e perspectivas. No sentido mais comum da palavra, é a primeira fase da vida de uma pessoa. Mas também pode ser entendida como algo mais abstrato, referindo-se a um período de inocência no qual a criança acredita em contos de fadas e no Papai Noel. Também pode ser entendida como a fase das brincadeiras e de viver sem muitas obrigações, pois nessa época as crianças ainda não têm grandes preocupações acerca da vida. É nesse sentido que, embora todos passem por essa fase, ainda se possa dizer que alguém "não teve infância". A infância também pode ser relacionada a certa ingenuidade ou inconsciência sobre a vida, de tal forma que se costuma usar o adjetivo "infantil" com essa intenção.

No contexto histórico, o conceito de infância era irrelevante na Idade Média. Mais precisamente, não havia um grande entendimento do que era ser criança para os adultos. Logo depois dos primeiros passos, para sobreviver, era necessário que a criança, o adulto em miniatura, alcançasse a autonomia, aprendendo sobre o mundo a partir da observação e das práticas que copiavam dos mais velhos. A fase da infância passaria quase despercebida pela sociedade medieval, se não fossem considerados os primeiros meses de vida, nos quais as crianças eram tratadas como uma distração, sobretudo pelas classes abastadas (ARIĖS, 1975).

O cenário é modificado somente a partir do século XVII, principalmente, pelo surgimento das escolas. Diante da necessidade de preservar a familia, as familias burguesas nascentes tornaram-se mais afetivas. O papel de educar e ensinar foi destinado às escolas, para preparar. de um lado, os jovens oriundos da burguesia na manutenção do patrimônio, de outro, a população para o trabalho. Essa modificação elevou a importância das crianças na estrutura familiar. Se compararmos a importância que é atribuida à fase da infância agora, com a indiferença que the atribuiam na Idade Média, sem dúvida ocorreram muitas evoluções (ARIĖS, 1975). 
Analisando o contexto literário a partir desse aspecto social abordado por Philippe Ariès, entende-se que a infância nem sempre foi um tema relevante para a literatura, já que os interesses voltados a elas eram outros. Segundo Amarilha (2000), as crianças começaram a abrir espaço no mundo literário apenas depois do surgimento de escolas e quando se passou a produzir literatura para fins de letramento das crianças. Essa literatura direcionada ao público infantil era pouco complexa, se tomada em comparação àquela entendida como adulta, o que a fazia ser entendida como "menor".

A criança ainda não era vista em suas peculiaridades cognitivas e psicossociais, nem em sua autonomia de pensamento e, por isso, as histórias eram produzidas com o intuito de educar e de "passatempo". De certa forma, no modo como a intenção criativa da literatura produzida para crianças era bastante diferente da adulta, é de se compreender que personagens e histórias infantis não tenham sido elementos das obras que compunham o cânone ainda no século XIX, com algumas poucas exceções, por exemplo, nos romances de formação, como As aventuras de Huckleberry Finn (1884), de Mark Twain, quando a perspectiva é adulta e os dramas das personagens correspondem ao pensamento adulto, ainda que as crianças vivenciassem desafios e experiências como aquelas do protagonista. No Brasil, temos o exemplo bastante conhecido de Através do Brasil (2010), de Olavo Bilac e Manoel Bonfim, cujo narrador coloca palavras e pensamentos adultos como se fossem dos jovens protagonistas, manifestando uma evidente intenção instrutora e moralizante.

No cenário brasileiro, conforme Amarilha (2000), Monteiro Lobato foi o primeiro escritor que conseguiu representar as expressões do público infantil na obra $A$ menina do narizinho arrebitado (1921). A obra é protagonizada por crianças, representando a essência da infância, pois, ainda que apresente um aspecto educativo, a sintaxe infantil é priorizada: seu modo de ver o mundo e de se comunicar com ele. Obras que tragam questões humanas protagonizadas por crianças, sem o viés e o julgamento adultos, são aquelas que podemos realmente entender como "literatura infantil". Mas compreendermos a representação da infância na literatura também envolve trazer à tona personagens e histórias que fingem, tipificam ou falseiam essa perspectiva. Por outro lado, não podemos esquecer que todas essas histórias produzidas para as crianças são escritas por adultos.

A temática infantil está presente nas duas coletâneas de contos de Monique Revillion, Teresa, que esperava as uvas e O Deus dos insetos; na primeira, composta por trinta e seis contos, oito apresentam a criança como personagem: "Bolinha", "Uma história de M", "Epitáfio", "Falar carioca em Xangri-lá", "A luz da aurora", "Estátuas", "Dez anos, Beatriz" e "Mistifório"; na segunda, composta por onze contos, três apresentam: "Atravessar oceanos", "No avesso" e "Memorial".

Em grande parte desses contos em que a infância é tematizada, os narradores voltam ao passado para contar algo que marcou esse período em suas vidas (em certo sentido, entre uma infância e uma não infância), (re)construindo personagens crianças. O olhar desses narradores se volta para alguém que já foram no passado, com uma visão modificada pelo tempo e pelas experiências que ele permite. Neste contexto, a análise se volta para uma representação da criança aos olhos de um adulto, para adultos. Por esse motivo, representar a criança e suas vivências nessas narrativas se torna mais complexo ainda.

Colocada em cena, a infância é representada,
ou seja, os escritores apresentam outra vez
aquilo que o leitor já conhece. No entanto, essa
apresentação não ocorre sem modificações
[..... A perspectiva da infância apresentada na
literatura fala em nome próprio. A criança não
é reconhecida como escritor. Sendo o ofício
do escritor apresentar diferentes pontos-de-
-vista, é mediada pela voz do adulto que a voz
da criança, ou uma idéia [sic] de infância, vai
poder ser lida na literatura (MATA, 2006, p. 9).

Para representar personagens infantis e, assim, a sintaxe do pensamento e da fala infantis, sua perspectiva sobre o mundo, o autor precisa ter noções de perspectiva. Quando se escreve sobre uma criança, sobre seus sentimentos e suas ações, é preciso uma posição empática - que 
torne possivel, também, dialogar com o leitor criança, quando essa obra se direcionar a esse público leitor. A tarefa de construir esse personagem se complica no fato de a criança fazer parte do campo literário apenas como leitora, ou seja, não temos acesso à complexidade de seu pensamento imaginativo pela linguagem literária. Esse distanciamento e essa assimetria fazem com que a representação da criança se torne menos próxima da realidade. (MATA, 2006, p. 10)

A representação de uma voz infantil em um texto pode ser considerada

[...] um atestado de superação da infância. Artificiosa, essa fala quase sempre é elaborada por um autor/narrador/personagem adulto que retoma uma infância, sua ou não. Desse modo, ela contém em si mesma o atestado de que não é uma fala infantil, pois o in-fante não fala, não diz, não se faz ouvir. Essa aparente impossibilidade, no entanto, tenta ser superada pelo exercício da memória ou da observação. É ai que entra o narrador que lembra ou o narrador que descreve. A infância, nesses casos, surge como nostalgia ou trauma, na memória; encantamento ou perversidade, na observação (MATA, 2015, p. 17)

Em muitos casos, a narrativa de memórias é usada como estratégia para a construção de personagens infantis. Mata (2015) destaca o uso de uma voz narrativa que não parece representar a criança no presente, mas um adulto narrador que relembra alguns momentos importantes da vida dele ou não. Este narrador constrói uma trama a partir de memórias baseadas na emoção que certos acontecimentos ou a lembrança deles o fazem sentir. Ainda segundo Mata (2015), essa narração é bastante complexa, o que torna visivel uma narração não infantil propositalmente, visto que intenta refletir sobre os acontecimentos a partir do presente adulto. Em vista disso, a criança nem sempre é representada de forma coerente na literatura e, muitas vezes, as ações, os sentimentos e o comportamento da personagem podem não corresponder àquilo que uma criança realmente seria capaz de fazer ou sentir.

Os personagens dos contos de Monique Revillion são geralmente representados pela recordação de memórias, através das quais o adulto reconstrói um acontecimento marcante e o revive através da narração, a partir de um presente adulto. Esse é o caso mais frequente na literatura que traz personagens crianças, como vemos, por exemplo, na coletânea Os meninos crescem (1977), de Domingos Pellegrini, cujos contos trazem personagens crianças em diferentes situações. Pellegrini consegue apartar-se de seu repertório adulto, deixando lacunas sobre o significado do acontecimento para o narrador adulto, ainda que esse narrador narre em primeira pessoa. Interessa-nos também, na obra de Revillion, os casos em que, embora o narrador seja em terceira pessoa, o tom da narração evoca uma aproximação intima entre ele e a criança protagonista, fazendo pensar que ele trata o acontecimento como se não fosse seu justamente para não trazer o sentimento adulto, muitas vezes perturbado, na reconstrução de uma memória que, na verdade, é dele.

O conto "Bolinha", do livro Teresa, que esperava as uvas, é um exemplo desse caso. Narrada em terceira pessoa, a história nos apresenta um menino que descobre o amor e a felicidade em um só momento: o dia em que encontra um filhote de cachorro. Depois de a mãe deixar o menino adotar o cachorro, chega a hora de escolher um nome para o bichinho. E é então que percebemos a influência adulta do narrador na descrição que justifica a escolha do nome, mais especificamente no trecho: "Porque lembrava uma esfera no infinito contido e porque eram redondos seus olhos e todo afeto incabivel nos ângulos retos, o nome surgiu na facilidade de coisa sabida: 'Bolinha'" (REVILLION, 2006, p. 30).

Analisando esse trecho, percebemos a ocorrência de um acréscimo de detalhes sobre o motivo da escolha "Bolinha". Muito provável seria a criança ter escolhido este nome pelos olhos redondos do animal, como citado na história, e o diminutivo reforça essa ideia. A descrição, no entanto, acrescida dos elementos, "uma esfera no infinito contido" e "todo afeto incabível nos ângulos retos" mostra uma análise da escolha pelo olhar adulto, quer dizer, a memória modifica aquele instante do passado a partir de todas as experiências vividas. Essa justificativa, ainda que adulta, visto a construção abstrata, não se afasta da perspectiva infantil, pois que tenta trazê-la de 
volta a partir de um olhar sensorial e poético, bastante caracteristico da contista Monique Revillion.

O narrador em terceira pessoa é, assim, o adulto revisitando seu passado com um olhar modificado que, ao mesmo tempo, tentar evitar corromper aquela lembrança. Ele não se vê mais como aquele menino inocente, no entanto, e, por isso, descreve sua lembrança como se fosse de outra pessoa. Analisemos o trecho abaixo:

\begin{abstract}
Naqueles poucos minutos, a compreensão fez sua obra naquela rua esquecida, e o menino, dolorido, apodrecendo por dentro como fruta passada, sem mais poder olhar para a cadela renomeada ou para qualquer pessoa que encontrasse pelo caminho enquanto voltava para casa. Mudo, impassível, surdo a qualquer palavra sob o injustificável, para sempre incapaz de enxergar de novo todas as cores do dia, para sempre negada a confiança, eternamente proibida a inocência, Bolinha, nunca um esquecimento, e nele, nunca, nunca mais um menino (REVILLION, 2006, p. 33-34).
\end{abstract}

Essa repetição "nunca, nunca mais", reverbera a emoção do guardado que foi vivido e sentido. Ao longo do conto, alguns elementos incorporam sentimentos profundos do menino, caracteristicas de um narrador que possivelmente vivenciou as emoções descritas. A "rua esquecida" evidencia a narração de memória: o narrador não lembra o nome da rua, mas, sim, toda a tristeza que (ele, menino) sentiu ao descobrir que sua cachorrinha tinha sido doada.

O patrimônio de reminiscências faz, portanto, do personagem um cativo de suas lembranças. São lembranças que se vão ancorar nos longes da infância, e que ganham vida, novamente, pelo sopro renovador da narração (COUTINHO, 2012, p. 115).

Trechos dos acontecimentos, assim, se perderam, ou seja, ficaram na memória apenas os detalhes que mais marcaram o menino, hoje, adulto, modificado. São essas lembranças, a seleção da memória, que se tornam matéria literária: local do primeiro encontro, os traços da cachorrinha, detalhes minuciosos que envolvem o amor que o menino sentia (e ainda sente) por Bolinha. É nesse sentido que o conto, embora presentificado pela adultez do narrador, coloca em foco um drama infantil. Vejamos que não há um paralelo com nenhum adulto, o narrador focaliza sempre o menino.
A infância surge no modo como o narrador seleciona os acontecimentos no tempo, a partir de vivências que aquela criança guardou. São características de uma narrativa memorialística que reconstrói um acontecimento com foco nos sentimentos da personagem. Conforme Ramirez (2011), as pessoas não têm controle sobre a memória, e sim ela sobre as pessoas. Desta forma, a escrita pode ser caracterizada como um instrumento que potencialize, conforme suas palavras, o "domínio da memória sobre o indivíduo" (RAMIREZ, 2011, p. 120).

Grande parte dos contos de Monique Revillion que apresentam a temática infantil estão intimamente ligados a escrita de memória - o fato distante no tempo e, por isso, marcado pela reflexão do adulto. Muitas vezes, essas personagens crianças são descritas e moldadas por seu "eu" adulto, às vezes em primeira pessoa, evocando passagens que envolvem lembranças de algum tipo de violência. Aparentemente, a abordagem desse tipo de tema relacionando-o a infância, é bastante comum, como destaca Mata:

A relação intima entre infância e violência
salta aos olhos de quem pesquisa o tema. As
ciências sociais, a psicologia e a imprensa têm
dedicado muitas páginas ao tema que, de fato,
requer soluções urgentes (MATA, 2006, p. 14).

O tema da violência não é incomum em obras que apresentam a infância, mas se direcionam ao leitor adulto, levando ao que entendemos como a representação de uma não infância. Na obra de Monique Revillion, a maioria dos contos retrata tipos de violência sofridas pelas crianças. Dentre os tipos de violência, a mais presente na obra é a sexual.

\section{A memória da violência na infância}

Analisando a narrativa de temática infantil nos contos de Monique Revillion, podemos categorizar três tipos:

a) a narração de memórias em primeira pessoa com um narrador adulto que revive um acontecimento marcante de sua infância; 
b) a narração pela "voz infantil" em primeira pessoa, que descreve um acontecimento, uma tentativa de representação da visão da criança sobre o ocorrido;

c) uma narrativa em terceira pessoa com uma visão menos íntima do ocorrido, mas ainda próxima do personagem, que às vezes parecem, como já comentado, "fingir" que estão para além da história.

Dentre os contos que se encaixam na primeira tipologia, podemos citar: "A luz da aurora", "Estátuas", "Mistifório", "No avesso" e "Memorial". Na segunda tipologia, são dois contos: "Falar carioca em Xangri-lá" e "Dez anos, Beatriz". Na última categoria, os contos que se encaixam são: "Bolinha", "Uma história de M", "Epitáfio" e "Atravessar oceanos".

"A luz da aurora" nos apresenta uma infância de pobreza e sofrimento, na qual o narrador provoca a morte da familia com vazamento de gás de cozinha. Em quatro páginas, apenas, é possivel compreender os motivos que fizeram o menino agir dessa forma, principalmente motivado pelo consentimento da mãe. Com uma temática mais leve, "Mistifório" apresenta um narrador que relembra seus dias com os primos na casa da avó, destacando cheiros, sabores e brincadeiras. "No avesso" nos mostra um narrador um pouco confuso com as lembranças dos dias em que ficava, junto com outras crianças, sob os cuidados de "Tia Ceci". Em "Memorial", acompanhamos a infância de um menino e sua familia, que sofria constante violência por parte do pai, até que este acaba por desaparecer em uma enchente.

"Falar carioca em Xangri-lá" é, provavelmente, o conto mais leve da obra de Monique Revillion. A narradora é uma criança que descobre o primeiro amor ao acaso, enquanto estava de férias na praia. A menina se surpreende ao descobrir que gostava tanto assim de alguém que sempre esteve ao seu lado. "Bolinha" é um conto que já citamos anteriormente, no qual um menino perde toda sua inocência ao descobrir a "traição" da mãe. "Epitáfio" é a história de uma menina e sua relação com seus animais de estimação, com um toque de sadismo infantil. "Atravessar oceanos" apresenta um menino cheio de esperanças, que tem seu sonho ceifado pela violência, assim como em muitos outros contos de Monique Revillion.

\begin{abstract}
A violência tem se feito presente de forma crescente no mundo, sendo enfocada pelos meios de comunicação sob diferentes representações: desde a domiciliar até os grandes conflitos armados. Em comum, as diferentes formas com que se apresenta, elege como vitimas os mais fracos. Nesta categoria encontram-se as crianças que nascem com total falta de defesa e perduram durante tempo prolongado na dependência de outros (adultos) (SCHERER, E.; SCHERER, Z., 2000, p. 22).
\end{abstract}

Ao analisarmos a temática infantil na obra de Monique Revillion, procuramos encontrar subtemas que sejam recorrentes. Ao constatarmos que o tema da violência se faz presente em vários dos contos, de formas distintas, optamos por categorizar dois tipos: a violência sofrida pela criança e a violência cometida por elas. O primeiro tipo é o mais significativo em números, a maioria retrata casos de assédio, violência doméstica e abusos. O segundo tipo pode ser um pouco perturbador. e é o menos comum. Afinal, as crianças podem ferir com intencionalidade? Analisando o conto "Estátuas", do livro Teresa, que esperava as uvas, podemos dizer que sim.

A narradora de "Estátuas" se encaixa na primeira categoria de contos, com narração de memórias em primeira pessoa. Ela relembra seus dias de infância entre seis amigos, quatro meninas e dois meninos. A brincadeira adorada por todos era justamente "estátua", na qual todos se reuniam em uma casa abandonada. Um por um, subiam no muro de tijolos, enquanto outro ficava embaixo, esperando para puxar a próxima criança conforme a intensidade escolhida: foguinho, fogo, fogão. Miranda é uma das seis crianças e apesar de sempre escolher fogão, caía em "pose de bailarina". Evidentemente, as outras meninas ficavam intimidadas com a menina, afinal, ela era a única que ia ao ballet.

Aparentemente, seria mais uma história normal de crianças brincando, não fosse o desfecho do conto e o que acontece um pouco antes do final, o clímax. As três meninas, na ausência dos meninos e de Miranda, que estava na aula de ballet, arquitetam um plano que parece incabivel no mundo das crianças. É neste momento que 
a narração nos leva para um lado sombrio e desconhecido da infância: o sadismo.

Então, na ausência dos meninos, falou-se em Miranda, a exibida, a casca de ferida. Por certo a primeira palavra teve autoria precisa, mas a intenção, de coletiva, emergiu sem resistências. [...] Quando Tonho apareceu com Augusto cheirando a cânfora, o plano já era fato quase consumado (REVILLION, 2006, p. 107-108).

Elas esperam até os amigos chegarem, os convidam para brincar de "estátua" e, com muita convicção, uma das meninas puxa Miranda do muro com todas as suas forças. O conto termina com Miranda gravemente ferida, talvez morta.

Esse tipo de narrativa pode ser um pouco surpreendente, pois a imagem que construímos acerca das crianças, certamente carregando um estereótipo, é totalmente diferente do que aparece na história. Apesar de não ser tão comum, existem outros escritores que abordam o lado violento das crianças. Mata (2006) destaca que:

Essa condição passiva da infância na narrativa da literatura brasileira encontra superação definitiva em Clarice Lispector, criadora de crianças como a Sofia, de "Os desastres de Sofia", que tortura psicologicamente seu professor, ou a filha do livreiro de "Felicidade clandestina"16, que de modo perverso adia indefinidamente o dia em que vai emprestar à narradora o livro que ela tanto quer. Se a infância segue a ser narrada a partir da mutilação de sua inocência, as meninas de Lispector também são capazes de agir, de mutilar, inclusive a si mesmas. Entra em cena não apenas o sofrimento imposto por outro, mas também o sadismo da infância" (MATA, 2006, p. 13).

O conto "Estátuas" nos apresenta a perspectiva mais oculta do mundo infantil, com uma imagem de criança mais humanizada. Segundo Resende (1988), a criança apresenta, assim como o adulto, comportamentos diversos desde pequena. Nem sempre a criança será inocente, pois pode cometer atos de perversidade, mas também de bondade. Resumidamente, muitas vezes as crianças são interpretadas como seres incapazes de cometer qualquer ato ruim, simplesmente porque carregam consigo um estereótipo de inocência.

Partimos agora, para a análise de outro tipo de violência recorrente nos contos de Monique Revillion: a violência sexual, na qual a criança é a vítima. O primeiro conto que vamos analisar é "Uma história de M". Esse conto do livro Teresa, que esperava as uvas nos apresenta a vida de "M". Narrado em terceira pessoa, o que chama a atenção é justamente a forma como o narrador retrata a personagem, nomeando-a apenas como "M, 6" ("M, 8" "M, 11" e "M, 12"). Segundo Cardoso (2017), a não nomeação da personagem Negrinha de Monteiro Lobato, caracteriza um "não ser". Como se a menina não existisse, por isso a inutilidade do nome. O mesmo ocorre com "M", a menina não existe aos olhos da sociedade. A própria violência a despersonifica.

"M" é uma criança em situação de rua, que convive dia a dia com a fome, o desprezo e a violência. O narrador nos mostra uma visão muito próxima da menina, relatando o que ela sabe e o que ela não sabe acerca das coisas do mundo. 0 início de cada parágrafo, por exemplo, apresenta um indicativo da idade de "M" naquele momento, além de uma descrição de que a menina "nada sabia sobre o poder e a dominação de uns sobre outros". Essa repetição no início de cada parágrafo reforça a construção da personagem a partir da infância - sua idade - demarcando a sua inocência perante toda a violência que atinge as pessoas ao seu redor e, consequentemente, ela mesma.

Violência não se limita apenas quanto a agres-
são fisica, mas também se direciona na possibi-
lidade de quem possui a dominação de poder,
inculcando valores, hábitus, comportamentos,
na qual a vitima que sofre esse tipo de violência,
mesmo que simbólica será afetada, sentindo-se
inferior aos demais grupos (BEIJO, 2018, p. 12).

O narrador deste conto enfatiza a não compreensão da menina acerca do quão violento é para si mesmo "mostrar os peitinhos" (REVILLION, 2006, p. 41) para motoristas em troca de dinheiro. Isso porque ela desconhece outra realidade, aquela em que uma criança vive e é tratada como tal. O mais próximo que " $M$ " chega dessa infância é quando consegue ver outras crianças nos carros que pararam nas sinaleiras. Nesse momento, ela descobre que essas crianças são apenas parecidas com ela, mas, "ao mesmo tempo, eram diferentes demais para que se reconhecessem" (REVILLION, 2006, p. 41). 
Com 8 anos, "M" passa por um evento de abuso e ela consegue compreender que isso aconteceu. Um homem a leva para longe, em uma rua sem saída e pede para que ela faça sexo oral nele. Depois, entrega dez reais para a criança e vai embora. A menina vai para a casa da tia nesse dia e chora pensando no que aconteceu. Depois desse acontecimento, "M" com 12 anos não consegue imaginar uma vida diferente, ela acredita que seu destino será sempre o de viver nas ruas, limpando vidros de carros ou "chupar algum motorista" e "sentar sobre o pau deles". Neste momento, percebemos que a linguagem se modifica, para dar espaço a esse universo em que a perda da infância se concretiza.

No penúltimo parágrafo, " $M$ " cospe em uma mulher que disse para ela "esfregar privadas e não arranhar o vidro do carro com aquele pano imundo" (REVILLION, 2006, p. 44). Quando os policiais jogaram a menina na viatura, o narrador destaca que esse instante foi o mais perto que " $M$ " chegou de compreender "o que é o poder e seus jogos de dominação e controle" (REVILLION, 2006, p. 44). Os policiais levam "M" para uma rua distante, que ela não reconhece, mas sabe que não é na delegacia. Nesse momento, ela pensa que queria muito um abraço da mãe, mesmo não lembrando muito de seu rosto. Também imagina o que poderia oferecer em troca da liberdade, "poderia trepar com aqueles três se gostassem de uma guria nova" (REVILLION, 2006, p. 45).

É desse modo, assim, que o conto retrata a não infância de uma criança que vive invisivel aos olhos de muitas pessoas. Muitos dos motoristas sequer olhavam para " $M$ " enquanto ela buscava alguma forma de ganhar dinheiro. Enquanto outros se apropriavam de seu "poder e dominação" para manipular uma criança com fome. As violências que "M" sofreu não eram explícitas para ela, principalmente porque ela desconhecia outra realidade, como podemos observar no trecho:

Mais tarde, M, 12 [...] imaginou que nunca poderia fazer outra coisa além de se aproximar dos carros para limpar os vidros fingindo ignorar que já ligavam o limpador de pára-brisa [sic], esguichando água para deixar claro que não queriam que ela chegasse perto. [...]. Também, às vezes, ela ia chupar algum motorista ou sentar sobre o pau deles ou deixar que eles enfiassem por trás [...] (REVILLION, 2006, p. 43).

Por fim, analisamos o conto "Dez anos, Beatriz". A narradora-personagem deste conto nos apresenta a história do dia em que foi violentada pelo irmão mais velho de uma amiga. Importante ressaltarmos que esse conto se encaixa na tipologia que representa a perspectiva da criança sobre o ocorrido, portanto, uma voz infantil. Às vésperas de completar dez anos, sua amiga Beatriz lhe revela coisas importantes: qualquer pessoa que está perto de completar dez anos deve cumprir alguns rituais de passagem; caso contrário "um velho" buscaria essa pessoa e a levaria embora. A narradora, na inocência de seus nove anos, acredita no que Beatriz fala, afinal, a amiga é mais velha, provavelmente já deve ter passado pela mesma coisa. Um dia antes do aniversário, o último passo para cumprir o ritual é revelado: a menina deve entrar no banheiro enquanto o irmão de Beatriz está tomando banho de banheira. Nesse momento o abuso acontece.

Ao longo do conto, podemos perceber quão articuladas são as informações que Beatriz passa para a narradora. É latente que a menina mais velha também já haveria passado pela mesma coisa. A violência, nesse conto, aparece de modo mascarado para a personagem. O irmão mais velho de Beatriz arquitetou uma forma para que a menina temesse a própria vida, caso não cumprisse com os "rituais".

Diferentemente dos dois outros contos analisados anteriormente, "Dez anos, Beatriz" nos mostra duas perspectivas acerca da infância. A primeira é a infância da narradora, vítima de um abuso que lhe causou um grande trauma, como podemos perceber no trecho: "Naquele Natal, não aceitei nenhum presente e quase fiquei feliz quando nos mudamos para uma casa menor" (REVILLION, 2006, p. 114). A segunda perspectiva de infância apresentada é a de Beatriz, que conta uma história na qual a narradora-personagem acredita e ocasiona um evento de abuso. Não podemos afirmar que Beatriz seja uma criança sádica, até mesmo existe a possibilidade de que ela mesma tenha passado por igual situação, manipulada 
pelo irmão. De qualquer forma, ela manipula a amiga, fazendo-a prometer não contar a ninguém sobre os rituais que deve cumprir. Neste último conto, portanto, a infância aparece apresentada de modos distintos.

\section{A não infância nos contos de Monique Revillion}

A abordagem da temática infantil na Literatura é bastante complexa. Essa complexidade se deve, principalmente, pela representação de personagens infantis a partir de um escritor adulto, seja através de um narrador adulto seja através de um narrador "criança". Além disso, a obra de Monique Revillion é uma literatura direcionada também ao público adulto, o que torna a representação de personagens infantis ainda mais complexa.

Essa complexidade é bem representada pela consistência dos múltiplos narradores da obra. Alguns buscam representar a visão da criança acerca dos acontecimentos, evitando o julgamento que as experiências e o repertório do adulto possibilitam. Outros narradores, também vozes adultas, revivem seus passados e se deixam levar pela memória. Ou, ainda, há narradores que apresentam uma visão de fora do ocorrido. Todos esses tipos trazem algo em comum: a narração de um evento marcante na vida dessas crianças, por muitas vezes traumático.

Os contos analisados nos mostram como a obra apresenta a temática infantil de formas diversas. As histórias trazem crianças em diversas situações: o primeiro amor, o primeiro bichinho de estimação, o sonho de jogar futebol; no entanto, mais diretamente, ou nas entrelinhas, a violência aparece com suas marcas. Procuramos encontrar, dentre todas estas variações, um subtema que estivesse presente na maioria dos contos. As crianças da narrativa de Monique Revillion sofrem com abusos e com a violência doméstica e às vezes podem ser as "vilãs", o que coloca ainda mais peso na responsabilidade do adulto. Considerando os principais conceitos do que é ser criança, podemos entender que em alguns dos contos os personagens não viveram a infância. $A$ violência, presente no dia a dia dessas crianças, dilacera a inocência e os sonhos e torna impossivel as lembranças felizes da infância. É nesse sentido que entendemos que um dos temas dos contos de Monique Revillion é a "não infância".

\section{Referências}

AMARILHA, Marly. Infância e literatura: traçando a história. Revista Educação Em Questão, Natal, v. 11, n. 2, p. 126-137, 1999. Disponivel em: https://periodicos.ufrn. br/educacaoemquestao/article/view/9497. Acesso em: 14 nov. 2020

ARIĖS, Philippe. História social da criança e da família. Tradução de Dora Flasksman. Rio de Janeiro: LTC Livros Técnicos e Científicos Editora S.A, 1981

BEIJO, Simone Lucinda Cordiro. Infância, educação e literatura infantil: um estudo sobre a violência simbólica nos contos. 62 f. Monografia apresentada à Federação Universidade Federal de Rondônia - UNIR (Curso de Pedagogia), Rolim de Moura, 2018. Disponível em: http://ri.unir.br/jspui/handle/123456789/2777. Acesso em: 16 nov. 2020

CARDOSO, Lais de Almeida. A infância revisitada: um estudo sobre o protagonismo infantil na literatura brasileira ao raiar do século XX. 2017. Tese (Doutorado em Estudos Comparados de Literaturas de Lingua Portuguesa) - Faculdade de Filosofia, Letras e Ciências Humanas, Universidade de São Paulo, São Paulo, 2017. Disponivel em: https://doi.org/10.11606/T.8.2017.tde04082017-192107. Acesso em: 16 nov. 2020.

COUTINHO, Fernanda. Representações da infância na literatura. Rio de Janeiro: Edições Makunaima, 2012.

MATA, Anderson Luis Nunes da. O silêncio das crianças: representações da infância na narrativa brasileira contemporânea. 2006. 116 f. Dissertação (Programa de Pós-Graduação em Literatura) - Universidade de Brasilia, Brasilia, 2006

MATA, Anderson Luis Nunes da. Infância na literatura brasileira contemporânea: tema, conceito, poética. Estudos de Literatura Brasileira Contemporânea, Brasilia, n. 46, p. 13-20, dez. 2015. Disponivel em: https://doi. org/10.1590/2316-4018461. Acesso em: 7 out. 2020.

RAMIREZ, Paulo Niccoli. A memória e a infância em Marcel Proust e Walter Benjamin. Revista Aurora: São Paulo, n. 10, p. 119-134, 2011. Disponivel em: https:// revistas.pucsp.br/aurora/article/view/4424. Acesso em: 18 nov. 2020

RESENDE, Vania Maria. O Menino na Literatura Brasileira São Paulo: Editora Perspectiva, 1988.

REVILLION, Monique. O Deus dos insetos. Porto Alegre: Dublinense, 2013.

REVILLION, Monique. Teresa, que esperava as uvas: contos. São Paulo: Geração Editorial, 2006. 
SCHERER, Edson Arthur:; SCHERER, Zeyne Alves Pires. A criança maltratada: uma revisão da literatura. Revista Latino-Americana de Enfermagem, Ribeirão Preto, v. 8 , n. 4 , p. 22-29, ago. 2000.

\section{Kelin Camila Beilke}

Licenciada em Letras Português - Licenciatura Plena pela Universidade de Santa Cruz do Sul (Unisc), em Santa Cruz do Sul, RS, Brasil.

\section{Ana Cláudia Munari Domingos}

Pós-Doutora em Intermidialidade pela Linnéuniversitetet, em Växjö, Götaland, Smöland; Doutora em Teoria da Literatura pela Pontificia Universidade Católica do Rio Grande do Sul (PUCRS), em Porto Alegre, RS, Brasil. Professora do Programa de Pós-Graduação em Letras da Universidade de Santa Cruz do Sul (Unisc), em Santa Cruz do Sul, RS, Brasil.

\section{Endereço para correspondência}

Kelin Camila Beilke

Linha Curitiba, Interior

Candelária, RS, Brasil

Ana Cláudia Munari Domingos

Caixa Postal 1355

Ag. Central dos Correios

Rua Siqueira Campos, 1100

Centro Histórico, 90001-970

Porto Alegre, RS, Brasil

Os textos deste artigo foram revisados pela Poá Comunicação e submetidos para validação das autoras antes da publicação. 